\title{
Early-Life Environment and Adult Stature in Brazil: An Analysis for Cohorts born between 1950 and 1980*
}

\author{
Victor Hugo de Oliveira \\ IPECE \\ Brazil
}

\author{
Climent Quintana-Domeque \\ University of Oxford \\ United Kingdom
}

July 7,2014

\begin{abstract}
We study the relationship between environmental conditions at birth (GDP per capita and infant mortality rate) and adult stature using cohort-state level data in Brazil for the period 1950-1980. We find that GDP per capita, whose annual percentage growth rate was $4.8 \%$ during this period, not infant mortality rate, is a robust correlate of population stature in Brazil. Our results are robust to a battery of robustness checks. Using a useful bracketing property of the (state) fixed effects and lagged dependent variables (heights) estimators, we find that an increase in GDP per capita of the magnitude corresponding to that period is associated with $43 \%-68 \%$ of the increase in adult height occurring in the same time span. Income, not disease, appears to be the main correlate of Brazilian population heights in the second half of the 20th Century.
\end{abstract}

JEL Classification Codes: I12, O54.

Keywords: infant mortality, income, measured adult height, bracketing property, fixed effects estimator, lagged dependent variable estimator.

\footnotetext{
${ }^{*}$ Quintana-Domeque (corresponding author): University of Oxford, Department of Economics, Manor Road Building, Manor Road, Oxford OX1 3UQ, United Kingdom; climent.quintana-domeque@economics.ox.ac.uk. We thank Pedro Albarran, Carlos Bozzoli, Lola Collado, Jaume Garcia, John Komlos, Asier Mariscal, Catia Nicodemo, Sonia Oreffice, Vladimir Ponczek, Francesco Serti and four anonymous referees for helpful comments and suggestions. Oliveira acknowledges financial support from the Instituto de Pesquisa e Estratégia Econômica do Ceará (IPECE). Quintana-Domeque acknowledges financial support from the Spanish Ministry of Science and Innovation (ECO 2008-05721 and ECO 2011-29751). This is a substantially revised version of a previous paper, "Infant disease, economic conditions at birth and adult stature in Brazil", that circulated as a working paper (FEDEA DT 2009-33 and IPECE Texto para Discussão n.75 November/2009). Financial support from the Spanish Ministry of Science and Innovation (ECO2011-29751) is gratefully acknowledged. Any errors contained in the paper are our own.
} 


\section{Introduction}

Over the past three centuries humans in the developed world have become taller and live longer than ever before (Floud et al., 2011). The relationship between adult stature and life expectancy has been established in numerous studies (Batty et al., 2009, Jousilahti et al., 2000, Kock, 2011, Leon et al., 1995, Waaler, 1984), along with the link between environmental conditions in the year of birth for a given population, as measured by its disease environment and/or available resources, and its adult stature (Bozzoli et al., 2009, Peracchi and Arcaleni, 2011). Height is a marker of health and nutrition during the critical periods of growth in early life (particularly from conception to age 3), and taller individuals exhibit superior outcomes in a wide range of measures, from happiness or life satisfaction to wages or productivity (Case and Paxson, 2008, Deaton and Arora, 2009, Lundborg et al., 2009, Schultz, 2003). Not surprisingly, understanding the determinants of the changes in body size represents a key part of a comprehensive theory of development, and is of interest to a wide spectrum of researchers, from human biologists and historians to demographers and economists.

Leaving the role of genes aside, individual stature is a function of net nutrition, which depends on gross nutrition minus the demands exerted on it, mainly through disease, but also through physical exercise. At the population level, however, the role of genes appears to be less important than that of environmental conditions in determining stature (Silventoinen, 2003). For this reason, studies have focused on gross nutrition (typically proxied by GDP per capita) and disease burden (usually proxied by infant mortality or postneonatal mortality rates). ${ }^{1}$ Bozzoli et al. (2009) unveiled evidence that across a range of European countries and the United States there is a strong inverse relationship between post-neonatal (defined as the period from one month to one year of age) mortality and the mean adult

\footnotetext{
${ }^{1}$ Infant mortality rate is measured as the number of infants who die in their first year of life per 1,000 live births. Post-neonatal mortality rate is measured as the number of infants who die between their first month and their first year of life per 1,000 live births.
} 
height of those infants in the same birth cohort who survived into adulthood. ${ }^{2}$

A very intriguing finding is that disease, not income, has been the constraining factor on human growth in developed countries at least after 1950 (Bozzoli et al., 2009, QuintanaDomeque et al., 2011). As pointed out by Bozzoli et al. (2009), and recently emphasized by Coffey (2013), this does not rule out the possibility that income (or nutrition related) constraints were important before 1950 or even nowadays in the more developing world. Indeed, this possibility echoes the work by Komlos (1998), who argues that the decline of average stature in Europe and North America during historical periods of economic growth ${ }^{3}$ was associated primarily with economic processes and structural changes (e.g., increase in income inequality, increase in relative price of nutrients) than a deterioration of the disease environment. It is also entirely consistent with Fogel's research (2004) on the links between income and height. In this paper, we explore the relationship between early-life environment, as measured by income and infant mortality in the year of birth, and the stature of the population in Brazil, a large developing country. ${ }^{4}$

In Brazil, researchers have used data from the Pesquisa de Orçamentos Familiares (POF) to document positive correlations between stature and education, and stature and wages (Curi and Menezes-Filho, 2009), but also to investigate the determinants of individual height. Monasterio et al. (2010) show the average state GDP per capita of each individual up to 15 years old is one of the main correlates of individual adult stature, controlling for per capita family income, years of education, demographic characteristics, and income distribution. While their results indicate a positive (concave) relationship between adult stature and the mean GDP during 0-15 years after birth, they do not account for the burden

\footnotetext{
${ }^{2}$ More recently, Quintana-Domeque et al. (2011) find that, in Spain, a reduction in the infant mortality rate of 30 individuals per 1,000 is associated with an increase in average height of about $2.7 \mathrm{~cm}$, about $70 \%$ of the gain in average adult stature during the period 1961-1980. In Italy, Peracchi and Arcaleni (2011) find that economic conditions appear to matter more than disease burden for height for cohorts of men born between 1973 and 1978.

${ }^{3}$ Second half of the eighteen century in Europe and the 1930s and the 1940s in both Europe and North America.

${ }^{4}$ Clearly, there is a large practical and epistemological gap between the core intentions of our analysis and the data employed (in particular with regards to proxying gross nutrition by GDP per capita). The reader must be aware of the very general character of the correlations presented in this paper.
} 
of disease in the year of birth, a potential determinant of adult height which is correlated with GDP. Neglecting the (potential) influence of disease exposure during childhood on adult stature can be problematic, not only because of previous research documenting the effects of infant mortality rate (IMR) in the year of birth on adult height, but also given the findings in Alves and Belluzo (2004) that a rise in education, sanitation and per capita income contributed to the decline of infant mortality in Brazil during the period 1970-2000, and the sizeable correlation coefficients between average adult stature and environmental measures (IMR and per capita GDP) in the year of birth across Brazilian states. ${ }^{5}$

In this paper we put forward an answer to the question "What are the forces behind the Brazilian human growth in the second half of the 20th Century?" focusing on the role of both income and disease (and its potential interactions) in explaining population heights. Collapsing height data from the POF at the state and year-of-birth level and combining it to data on GDP, IMR and other socioeconomic indicators at the state-year level, we find that income, not disease, is a robust correlate of population stature in Brazil during the period 1950-1980. Using a useful bracketing property of the (state) fixed effects and lagged dependent variables (heights) estimators (Guryan, 2001; Angrist and Pischke, 2009), we find that an increase in GDP per capita of the magnitude corresponding to that period is associated with $43 \%-68 \%$ of the increase in adult height occurring in the same time span. Finally, we also show that per capita income five years before birth is not associated with adult height, whereas per capita income during the first five years of life is an important correlate of it.

The paper is organized as follows. Section 2 describes the data sources. Section 3 summarizes the evolution of height, GDP and IMR in Brazil during the period 1950-1980. Section 4 contains the main regression results. Section 5 provides several robustness checks. Section 6 concludes.

\footnotetext{
${ }^{5}$ The correlation between IMR and adult height is -0.65 (p-value $\left.=0.0000\right)$, between log of real per capita GDP and height is 0.79 ( $\mathrm{p}$-value $=0.0000$ ), and between IMR and log of real per capita GDP is -0.77 (pvalue $=0.0000)$. These pair-wise correlations conform to the existing empirical evidence coming from other studies, in terms of both signs and magnitudes. Section 2 provides the data sources.
} 


\section{Data Sources}

Height data come from the Brazilian Household Budget Survey 2002-2003 (Pesquisa de Orçamentos Familiares - POF) of the Brazilian Institute of Geography and Statistics (Instituto Brasileiro de Geografia e Estatística - IBGE), which provides information on gender, race, year of birth, state of current residence, and anthropometric information (weight and height). The main advantage of the POF survey with respect to many other datasets used in previous studies is that, apart from providing a representative sample of the Brazilian population, anthropometric measures are not self-reported, but actually measured. ${ }^{6}$ Height is collected by using a graduated tape measure in which fractions of centimeters are rounded to the nearest integer. Individuals aged 2 or above are measured in vertical position. ${ }^{7}$

The sample is restricted to individuals born in 1950, 1960, 1970 or 1980, who already attained their adult stature by the time the survey was carried out (i.e., aged at least 21 in 2002-2003). Furthermore, due to both mortality-related selection and shrinking of the elderly, our sample excludes individuals over age 53 in 2002-2003. ${ }^{8}$ The total number of individual observations is 8,350: 1,442 for the cohort born in 1950 (694 men and 748 women), 1,921 for the cohort born in 1960 (932 men and 998 women), 2,244 for the 1970 cohort (1,117 men and 1,127 women) and 2,743 for the 1980 cohort (1,447 men and 1,296 women). In order to increase the precision of our estimates, and following Bozzoli et al. (2009), we compute average height by year of birth and by state of current residence, by summing up the average heights from adult males and females and dividing by two (to avoid fluctuations due to gender mix). ${ }^{9}$

\footnotetext{
${ }^{6}$ Typically, studies that use measured anthropometric data are from selected populations.

${ }^{7}$ Anthropometric measures were submitted to the Critique and Imputation System for Quantitative Data (Crítica e Imputação para Dados Quantitativos, CIDAQ). http://www.ibge.gov.br/home/estatistica/populacao/condicaodevida/pof/2003medidas/microdados.shtm

${ }^{8}$ We only consider whites, blacks and "pardos" (browns in Monasterio et al., 2010). Natives and Asians are less than $1 \%$ of the total sample.

${ }^{9}$ We also perform part of our analysis for males and females separately. However, certain data limitations must be acknowledged in assessing these disaggregated estimates (see footnote 18).
} 
GDP and population size data for all Brazilian states and the years 1950, 1960, 1970 and 1980 come from IPEADATA. ${ }^{10}$ Per capita GDP is constructed as the ratio of GDP and population size, and converted to US Dollars using the real exchange rate $(2005=100)$ from the International Monetary Fund (IMF) website. ${ }^{11}$ Infant mortality rates and additional socioeconomic indicators (e.g. urbanization), for all Brazilian states and the years 1950, 1960, 1970 and 1980 are available in the statistics of the 20th Century produced by the IBGE. $^{12}$

\section{The Evolution of Height, Income and Disease in Brazil}

Table 1 summarizes the data on average height, infant mortality rate per 1,000 live births (IMR) and the logarithm of the real per capita gross domestic product (GDP) by four birth cohorts and the five Brazilian regions. ${ }^{13}$ Average height increased by about $3 \mathrm{~cm}$ in thirty years, from 162.6 to $165.4 \mathrm{~cm}$, for cohorts born in 1950 and 1980, respectively, which is about $1 \mathrm{~cm}$ per decade, and consistent with the evidence reported by Schultz (2005) using data from the 1989 Health and Nutrition Survey of Brazil (Pesquisa Nacional sobre Saúde e Nutrição). We note that the mean stature of the youngest cohort is $11.6 \mathrm{~cm}$ lower than that of Denmark and $2.6 \mathrm{~cm}$ lower than that of Portugal, the taller and shorter European cohorts

\footnotetext{
${ }^{10}$ In particular, GDP is available at the state level annually from 1947 to 1970, and then in 1975, 1980 and 1985. Population size is available at the state level in 1950, 1960, 1970 and 1980. http://www . ipeadata.gov.br

${ }^{11} \mathrm{http}: / /$ www .imf .org/external/data.htm

${ }^{12} \mathrm{http}: / /$ seculoxx.ibge.gov.br. Although it would be interesting to perform the analysis decomposing IMR on neonatal mortality and post-neonatal mortality, as in Bozzoli et al. (2009) and Coffey (2013), these indicators are not available for before 1980 at the state level. The final dataset used in this paper is available at https://www.dropbox.com/s/1mzysydtqckit9r/dataset.dta. The replication (Stata do) file is available at: https://www.dropbox.com/s/5zqzhawavrz0x4c/replication.do.

${ }^{13}$ The breakdown of the five Brazilian regions into the 20 Brazilian states (in parentheses) is as follows: North (Amazonas and Pará), Northeast (Maranhão, Piauí, Ceará, Rio Grande do Norte, Paraíba, Pernambuco, Alagoas, Sergipe and Bahia), Southeast (Minas Gerais, Espírito Santo, Rio de Janeiro and São Paulo), South (Paraná, Santa Catarina and Rio Grande do Sul) and Center-West (Mato Grosso and Goiás). We only use data from these 20 Brazilian states because those are the ones with available information on IMR for the years 1950, 1960, 1970 and 1980.
} 
born in 1976-1980 in the study of Bozzoli et al. (2009). Compared to the US, Brazil is 6.6 $\mathrm{cm}$ below. There is higher variation at the regional level. For the oldest cohort the mean ranges from $159.8 \mathrm{~cm}$ in the North to $165.8 \mathrm{~cm}$ in the South, i.e. a gap of $6 \mathrm{~cm}$, while for the youngest it ranges from $163.8 \mathrm{~cm}$ in the Northeast to $168 \mathrm{~cm}$ in the South, i.e. a $4.2 \mathrm{~cm}$ difference. Cohorts from Southern regions are taller than cohorts from Northern regions, a gap that has been previously documented and discussed by Monasterio et al. (2010). Figure 1 (in the appendix) displays the regional time trends in adult stature, highlighting the differential "human" growth rates by region and the reduction in the gap between the shortest and tallest regions from 1950 to 1980.

Table 1 also reveals a sharp fall in infant mortality rate between 1950 and 1980, from 150 to 94 infant deaths per 1,000 live births, which reflects a decrease of (roughly speaking) 2 deaths per 1,000 live births per year. However, in 1980, the level of IMR in Northeast reached around 125 per 1000 live births, an order of magnitude similar to the one observed in SubSaharan African countries (122 in 1975-1980, World Population Prospects, 2010 Revision, United Nations). ${ }^{14}$ Indeed, while all regions experienced a substantial drop in IMR, from a reduction in 80 deaths per 1,000 live births in the North to 49 in the Center-West, regional disparities in the health environment are persistent across cohorts: A clear constant gap between the Northeast and the South is very visible in Figure 2 (in the appendix) both at the beginning and at the end of the period.

Finally, Table 1 shows an improvement in economic conditions during the period 19501980, with an annual percentage growth rate of real GDP per capita of about $4.8 \%$. As highlighted by Schultz (2005), economic growth is a potential relevant factor in explaining the human growth of the Brazilian population. Figure 3 (in the appendix) displays the regional time trends in $\log (\mathrm{GDP})$, highlighting the persistent income differential between the poorest and richest regions over the period under analysis. ${ }^{15}$

\footnotetext{
${ }^{14}$ http://esa.un.org/unpd/wpp

${ }^{15}$ Azzoni (1997) presents a very detailed analysis of the regional income inequality in Brazil.
} 
Table 1. Descriptive statistics by birth cohort and region

$1950 \quad 1960 \quad 1970 \quad 1980$

Adult Stature (cm)

\begin{tabular}{lllll} 
North & 159.8 & 161.3 & 162.1 & 163.9 \\
Northeast & 160.8 & 161.6 & 162.6 & 163.8 \\
Southeast & 164.5 & 164.3 & 166.7 & 167.2 \\
South & 165.8 & 165.4 & 166.2 & 168.0 \\
Center-West & 164.6 & 165.0 & 166.3 & 167.1 \\
Mean & 162.6 & 163.0 & 164.3 & 165.4 \\
\hline
\end{tabular}

\section{IMR (per 1,000 live births)}

\begin{tabular}{lcccc} 
North & 150.3 & 116.4 & 110.2 & 70.7 \\
Northeast & 176.2 & 168.7 & 153.8 & 124.5 \\
Southeast & 129.8 & 98.2 & 99.8 & 71.9 \\
South & 116.7 & 86.8 & 84.6 & 60.9 \\
Center-West & 119.5 & 95.7 & 101.5 & 70.7 \\
Mean & 149.7 & 129.8 & 123.0 & 93.7 \\
\hline
\end{tabular}

\section{$\log ($ GDP $)$}

\begin{tabular}{lllll} 
North & 6.7 & 7.2 & 7.4 & 8.3 \\
Northeast & 6.3 & 6.6 & 6.9 & 7.6 \\
Southeast & 7.4 & 7.6 & 8.1 & 8.8 \\
South & 7.3 & 7.5 & 7.8 & 8.7 \\
Center-West & 7.2 & 7.6 & 7.9 & 8.2 \\
Mean & 6.8 & 7.1 & 7.4 & 8.2 \\
\hline \hline
\end{tabular}

Note: $\log ($ GDP) is the log of real income per head.

See Footnote 12.

The set of stylized facts presented in this section are consistent with both income and disease at birth affecting the evolution of population heights in Brazil during the period 1950-1980. ${ }^{16}$ In the next section we use regression analysis to assess whether the evolution of income, mortality or both are indeed responsible for the increase in heights of the Brazilian population during the second half of the 20th century.

\footnotetext{
${ }^{16}$ Summary statistics by state and year of birth are provided in the appendix (Tables A1, A2 and A3).
} 


\section{Main Results}

Table 2 presents the main results of our study. It displays estimates from a series of regressions in which mean population height is the dependent variable. The first two columns consider the role of IMR. Column 1 shows that in the 80 pooled time-series cross-section observations for the 20 Brazilian states over 4 years of birth, variation in IMR explains $42 \%$ of the variation in average height. The parameter estimate is -0.045 , much lower than the one found in recent studies for developed countries (Quintana-Domeque et al., 2011). Column 2 includes both year of birth and region fixed effects. The explanatory power of the regression increases from $42 \%$ to $67 \%$ (adjusted $R^{2}$ s), the estimated coefficient on IMR flips its sign, and the relationship between height and IMR disappears.

\begin{tabular}{|c|c|c|c|c|c|c|c|}
\hline & (1) & (2) & (3) & (4) & (5) & (6) & (7) \\
\hline IMR & $\begin{array}{c}-0.045^{* * *} \\
(0.005)\end{array}$ & $\begin{array}{c}0.014 \\
(0.012)\end{array}$ & - & - & $\begin{array}{l}-0.007 \\
(0.007)\end{array}$ & $\begin{array}{c}0.009 \\
(0.010)\end{array}$ & $\begin{array}{l}-0.032 \\
(0.048)\end{array}$ \\
\hline $\log (\mathrm{GDP})$ & - & - & $\begin{array}{c}2.67^{* * *} \\
(0.22)\end{array}$ & $\begin{array}{c}2.07^{* * *} \\
(0.43)\end{array}$ & $\begin{array}{c}2.40^{* * *} \\
(0.36)\end{array}$ & $\begin{array}{c}2.02^{* * *} \\
(0.42)\end{array}$ & $\begin{array}{l}1.46^{*} \\
(0.75)\end{array}$ \\
\hline $\mathrm{IMR} \times \log (\mathrm{GDP})$ & - & & - & - & - & - & $\begin{array}{c}0.006 \\
(0.006)\end{array}$ \\
\hline Year dummy variables? & NO & YES & $\mathrm{NO}$ & YES & $\mathrm{NO}$ & YES & YES \\
\hline Region dummy variables? & $\mathrm{NO}$ & YES & $\mathrm{NO}$ & YES & $\mathrm{NO}$ & YES & YES \\
\hline$R^{2}$ & 0.42 & 0.70 & 0.63 & 0.77 & 0.63 & 0.77 & 0.77 \\
\hline Adjusted $R^{2}$ & 0.42 & 0.67 & 0.63 & 0.74 & 0.63 & 0.74 & 0.74 \\
\hline $\mathrm{N}$ & 80 & 80 & 80 & 80 & 80 & 80 & 80 \\
\hline
\end{tabular}

In columns 3 and 4 we shift our attention to real income per head (measured by the log of real GDP per capita, $\log (\mathrm{GDP}))$. Column 3 shows that $63 \%$ of the variation in average height is explained by income. The parameter estimate is 2.67 , which is similar to the estimate from Quintana-Domeque et al. (2011). Adding both year of birth and region fixed effects, column 4, does not affect the qualitative relationship between income and height, although the parameter estimate decreases to 2.07 . 
Finally, columns 5 to 7 consider the role of both disease and income simultaneously. In column 5, we show that conditional on GDP, IMR does not play any role in explaining average height, while GDP does. The addition of year of birth and region fixed effects, column 6 , does not change the qualitative relationship between income and height. In the last column we include the interaction of IMR and GDP. This new variable has no power in explaining average height, while IMR and GDP play the same role as in columns 5 and 6 .

The explanatory power of IMR (in column 1) is much lower than the one obtained in recent studies for developed countries for cohorts born between 1950 and 1980. In the cross-country cohort-study of Bozzoli et al. (2009) for several European countries and the United States, the post-neonatal mortality explanatory power is $62 \%$, similar to the $60 \%$ explanatory power of IMR in the very recent cross-region cohort-study of QuintanaDomeque et al. (2011) for Spain. In addition, IMR is not a robust correlate of population height. Although disease rather than income has been the constraining factor in developed countries at least after 1950, the story of human growth appears to be different in Brazil. ${ }^{17}$ Similar results are obtained when we estimate regressions separately for male and female heights (results reported in tables A4 and A5 in the appendix) on (estimated) gender specific infant mortality rates. ${ }^{18}$

However, before concluding that income is the driving force of population heights in Brazil, we must acknowledge that several factors could be interfering with our estimates, namely unobserved constant differences across states, migration patterns, the interaction between income and disease, and several omitted (or mismeasured) determinants of height that vary simultaneously at the state and year level. ${ }^{19}$ Next section provides a battery of

\footnotetext{
${ }^{17}$ Although we are taking averages over race/color, Monasterio et al. (2010) show that a significant part of the apparent variation by color is in fact a result of the differences in income between colors, not within color groups themselves.

${ }^{18}$ We compute gender specific infant mortality rates by year and state by assuming that the ratio between male and female infant mortality rates (available at the regional level in 1980 from http://seculoxx.ibge.gov.br) is the same in 1950, 1960 and 1970, and assuming that is the same among states within the same region. We thank John Komlos for suggesting this approach.

${ }^{19}$ What about mortality-related selection? If shorter people were more likely to die, we would expect sample selection due to mortality leading us to underestimate the negative effect of IMR and overestimate the positive effect of $\log (\mathrm{GDP})$. Using life expectancy at birth as a crude proxy for adult mortality (expected
} 
checks to assess the robustness of our results.

\section{Robustness Checks}

\subsection{State Fixed Effects versus Lagged Height Variables}

Our previous estimates account for both time variation through fixed effects and geographical variation through regional fixed effects. While there is great scope for omitted variable bias due to unobserved state differences (we have 5 regions and 20 different Brazilian states), controlling for state fixed effects could mean asking too much from the data, that is, we could be absorbing part of the true "effect" of the variables of interest (IMR and $\log (\mathrm{GDP}))$ on adult height. An immediate question is: Can we think of the state fixed effects estimator as providing a lower bound of the income effect on adult height? If so, can we think of finding an upper bound? We address this issue in Table 3.

In column 1 we display the estimates of the relationships between height, mortality and income once we control for year and state fixed effects. As before, we do not find a relationship between infant mortality in the year of birth and the average height of the corresponding cohort. In addition, we still find a positive and statistically significant relationship between average cohort height and the gross domestic product in the year of birth, although (as expected) the point estimate is halved with respect to that in column 6 of Table 2.

length of life) of the cohort under analysis, we can assess whether such biases are likely to be empirically relevant. When we include life expectancy at birth as an additional control variable in column (7) of Table 2 , we obtain the following point estimates (standard errors) for IMR and $\log (\mathrm{GDP}):-0.160(0.127)$ and 2.46 (1.38). These should be compared against $-0.032(0.048)$ and $1.46(0.75)$. If anything, the new point estimates go against the expected biases, since controlling for life expectancy makes the effects on IMR $(\log (\mathrm{GDP}))$ more negative (positive). Alternatively, one may decide to put more weight on observations with higher life expectancy. If we weight observations by life expectancy, we get essentially the same point estimates than without weighting: $-0.031(0.049)$ and 1.38 (0.76). Hence, sample selection due to mortality does not seem to affect our point estimates. 


\begin{tabular}{|c|c|c|c|c|}
\hline & State Fixed Effects & Lagged & Dependent & eights \\
\hline & $(1)$ & $(2)$ & $(3)$ & (4) \\
\hline IMR & $\begin{array}{c}0.019 \\
(0.014)\end{array}$ & $\begin{array}{c}0.000 \\
(0.005)\end{array}$ & $\begin{array}{c}0.002 \\
(0.008)\end{array}$ & $\begin{array}{c}0.013 \\
(0.009)\end{array}$ \\
\hline $\log (\mathrm{GDP})$ & $\begin{array}{l}0.841^{*} \\
(0.443)\end{array}$ & $\begin{array}{c}1.40^{* * *} \\
(0.383)\end{array}$ & $\begin{array}{l}1.50^{* *} \\
(0.547)\end{array}$ & $\begin{array}{c}1.34^{*} \\
(0.713)\end{array}$ \\
\hline Height in 1950 & - & $\begin{array}{c}0.516^{* * *} \\
(0.085)\end{array}$ & $\begin{array}{c}0.210 \\
(0.135)\end{array}$ & $\begin{array}{c}0.302 \\
(0.200)\end{array}$ \\
\hline Height in 1960 & - & - & $\begin{array}{c}0.374^{* * *} \\
(0.082)\end{array}$ & $\begin{array}{c}0.391^{* *} \\
(0.155)\end{array}$ \\
\hline Height in 1970 & - & - & - & $\begin{array}{c}0.145 \\
(0.193)\end{array}$ \\
\hline Year dummy variables? & YES & YES & YES & $\mathrm{NO}$ \\
\hline State dummy variables? & YES & $\mathrm{NO}$ & $\mathrm{NO}$ & NO \\
\hline$R^{2}$ & 0.66 & 0.79 & 0.83 & 0.92 \\
\hline Adjusted $R^{2}$ & 0.64 & 0.77 & 0.81 & 0.89 \\
\hline $\mathrm{N}$ & 80 & 60 & 40 & 20 \\
\hline
\end{tabular}

Instead of controlling for stated fixed effects, one could include lagged height (dependent) variables. Interestingly enough, the (state) fixed effects and lagged dependent variables (height) estimators have a useful "bracketing property" (under some conditions, see Angrist and Pischke, 2009; Guryan, 2001). In our case, this property can be roughly stated as follows: If $\log (\mathrm{GDP})$ is positively correlated with either lagged population height or with fixed determinants of lagged population height, then the state-fixed effect estimate and the lagged-height variables estimate should bracket the estimate of interest. In other words, the estimated (positive) effect of $\log (\mathrm{GDP})$ on height using stated-fixed effects will tend to be too small, while the estimated (positive) effect of $\log ($ GDP) using lagged-height variables will tend to be too big. This is precisely what we observe when we compare column 1 to columns 2 to 4 .

According to our estimates in Table 3, an increase in $\log ($ GDP) by 1.4 units - which is the increase experienced by average $\log (\mathrm{GDP})$ between 1950 and 1980 - would explain between $43 \%(1.2 \mathrm{~cm}=1.4 \times 0.84)$ and $68 \%(1.9 \mathrm{~cm}=1.4 \times 1.34)$ of the $2.8 \mathrm{~cm}$ increase in average height shown in Table 1. In the appendix, tables A6 and A7, we re-estimate 
Table 3 separately for men and women. The regression results in Tables A6 and A7 indicate that the relationship between gender-specific infant mortality rates and stature is not statistically different from zero, no matter whether we control for state fixed effects or lagged heights. Regarding the role of income, we find that controlling for lagged heights makes the relationship between income and stature weaker for females, while controlling for state fixed effects washes it out. However, these results must be taken with a grain of salt, since we do not have "gender-specific income". If mean income is a noisier measure of female "nutrition", the zero result for females could be just the product of an exacerbation of attenuation bias.

\subsection{Migration and exposure to income and disease environments}

Ideally, we would like to estimate the relationship between the average stature of a cohort and its corresponding infant mortality rate (or real income per capita) in its year of birth. ${ }^{20}$ This, of course, raises two main complications. The first is that for those currently living in Brazil and randomly selected in the POF survey, we know where they are currently living but not their place of birth. We cannot distinguish stayers (individuals living in their state of birth) from the rest of individuals in the POF data, and migrants are likely to be taller than stayers (e.g., Salvatore, 2009; Kopczyński, 2011). ${ }^{21}$ The second issue, and related to the first, is that even if this information was available, we would need to know, for those who actually moved, whether they migrated in the first year of life or after their first year of life but before the puberty growth spurt (van den Berg, Lundborg, Nystedt and Rooth, 2012). The lack of information on whether individuals move (and if so, when) makes us to be uncertain about whether the matching of average adult cohort heights by state to the

\footnotetext{
${ }^{20}$ As noted by Bozzoli, Deaton and Quintana-Domeque (2009), our matching of date of birth to IMR and GDP is inevitably imprecise at the level of a single year, if only because the income and disease environments that are relevant for adult height operate not just in the year of birth. This is not a problem since we are interested in allowing the data to pick up trends and changes in trends.

${ }^{21}$ Salvatore (2009) analyzes the stature growth in industrializing Argentina in the first half of 20th century and finds that internal migrants were shorter on average than natives of the industrial districts. Kopczyński (2011) shows evidence of selective migration from the provinces to the cities in Poland in the second half of the 19th century: short individuals remained in small towns, while taller individuals moved to the city.
} 
infant mortality rates and income levels in the year of birth for the same state is adequately capturing the relevant income and disease environments. For this reason, it is crucial to assess whether migration is biasing our previous estimates and to what extent.

If migration was random with respect to individual health (height), our estimated "effects" of both infant mortality and income would be biased towards zero. If not, then we could have either positive or negative biases. Suppose that migration went from poorer regions (in terms of both health status and income) to richer regions, and that healthier (i.e., taller) individuals were more likely to migrate to healthier and richer regions. In that case, we would be overestimating the positive "effect" of income on population heights, since poor regions would become shorter and richer regions would become taller through a compositional change. By the same token, we would be overestimating the negative "effect" of infant mortality on population heights. If instead of the healthy, those who decided to migrate were the unhealthy, then we would tend to underestimate the "effect" of income and mortality on population heights.

Our findings of no relationship between infant mortality and height could be explained by a compensating effect of shorter people born in high-mortality regions moving to taller and low-mortality regions, such that the negative biological effect on population height in the high-mortality region is compensated through a behavioral response from shorter individuals in this region moving to the low-mortality and taller region, so that the mean of both regions tend to approach, although the levels of infant mortality are different.

In order to investigate whether shorter people were more likely to migrate, we use the Life Standard Survey 1996/1997 (Pesquisa de Padrões de Vida, PPV) carried out by the IBGE in six Brazilian states (Ceará, Pernambuco, Bahia, Rio de Janeiro, São Paulo, Minas Gerais). Although the survey is not nationally representative, it includes states of the poorest region (Northeast - Ceará, Pernambuco, Bahia) and states of the richest region (Southeast - Rio de Janeiro, São Paulo, Minas Gerais). The PPV collects individual information on year of birth, place of birth, place of residence, and height. When we compute the average heights for 
individuals aged 20-53 by region of birth (Northeast vs. Southeast), distinguishing between "stayers" (individuals whose region of residence coincides with their region of birth) and "migrants" (individuals whose region of residence does not coincide with their region of birth), two findings emerge: First, individuals in the richest region are (on average) taller than those in the poorest region, regardless of whether they are stayers or migrants; Second, migrants tend to be taller (not shorter), regardless of their region of birth. Hence, we conclude that the results indicating non-significant effects are not driven by shorter people being more likely to migrate. These estimates are available upon request.

Finally, we use information on the fraction of stayers to adjust our previous estimates. To do that, we compute the proportion of individuals living in the same state of birth (i.e., stayers) for each specific birth cohort (1950, 1960, 1970 and 1980), using information from the 2003 National Household Survey (Pesquisa por Amostra de Domicílios, PNAD). ${ }^{22}$ Table 4 reports the proportions of stayers by regions. In all regions, but the North, the proportion of individuals living in the same state of birth increases monotonically over time (cohort). The Center-West region has the lowest fraction of stayers. During the second half of 20th Century inter-regional migration was intensive not only from poor regions (e.g., Northeast) to rich regions (e.g., Southeast), but also from poor and rich regions to low population density areas (Center-West and North).

Migration patterns in Brazil over the period under analysis are not negligible, and some correction must be applied to our previous estimates. We proceed in three different ways. First, we re-estimate regressions of columns 2, 4 and 6 from Table 2 retaining only those pairs of cohort-states with a high fraction (above 0.8) of individuals living in the same state of birth. This amounts to cutting the sample size by 26 observations, as we can see in columns 1, 2 and 3 of Table 5. Second, for the whole sample, in column 4 we weight each observation by the fraction of stayers, giving more weight to observations with a higher fraction of stayers, and in column 5 we include the fraction of stayers as an additional

\footnotetext{
${ }^{22}$ The PNAD is conducted by the Brazilian Institute of Geography and Statistics (Instituto Brasileiro de Geografia e Estatística - IBGE).
} 
explanatory variable. Finally, we use the bracketing property of the (state) fixed effects (FE) and lagged dependent (LD) variables (heights) estimators in columns 6 and 7 after accounting for the fraction of stayers. Reassuringly, the estimates displayed in this table indicate once again that income, not disease, is a robust correlate of height. Interestingly enough, once we account for the fraction of stayers, the bounds for the "true effect" of income on height become tighter, 1.05-1.39. Hence, we tentatively conclude that migration does not seem to interfere with our previous results.

\begin{tabular}{lcccc}
\hline \hline \multicolumn{5}{l}{ Table 4. Fraction of stayers } \\
& 1950 & 1960 & 1970 & 1980 \\
\hline North & 0.75 & 0.74 & 0.78 & 0.86 \\
Northeast & 0.86 & 0.89 & 0.91 & 0.92 \\
Southeast & 0.73 & 0.76 & 0.78 & 0.87 \\
South & 0.78 & 0.85 & 0.87 & 0.90 \\
Center-West & 0.44 & 0.46 & 0.53 & 0.67 \\
\hline \hline
\end{tabular}




\begin{tabular}{|c|c|c|c|c|c|c|c|}
\hline & \multicolumn{3}{|c|}{ Subsample } & \multicolumn{2}{|c|}{ Full sample } & \multicolumn{2}{|c|}{ Bracketing } \\
\hline & Fractio & of stay & rs $>0.8$ & Weighting & Without weights & State FE & LD Heights \\
\hline & (1) & $(2)$ & $(3)$ & (4) & $(5)$ & (6) & (7) \\
\hline IMR & $\begin{array}{c}0.010 \\
(0.013)\end{array}$ & - & $\begin{array}{l}-0.003 \\
(0.011)\end{array}$ & $\begin{array}{c}0.005 \\
(0.010)\end{array}$ & $\begin{array}{c}0.007 \\
(0.010)\end{array}$ & $\begin{array}{c}0.018 \\
(0.014)\end{array}$ & $\begin{array}{c}0.014 \\
(0.010)\end{array}$ \\
\hline $\log (\mathrm{GDP})$ & - & $\begin{array}{c}2.74^{* * *} * \\
(0.54)\end{array}$ & $\begin{array}{c}2.80^{* * *} * \\
(0.58)\end{array}$ & $\begin{array}{c}2.32^{* * *} \\
(0.43)\end{array}$ & $\begin{array}{c}2.23 * * * \\
(0.45)\end{array}$ & $\begin{array}{c}1.05 \\
(0.72)\end{array}$ & $\begin{array}{l}1.39 * \\
(0.76)\end{array}$ \\
\hline Fraction of stayers & - & - & - & - & $\begin{array}{c}2.08 \\
(1.81)\end{array}$ & $\begin{array}{l}1.30 \\
(2.37)\end{array}$ & $\begin{array}{l}-0.87 \\
(2.19)\end{array}$ \\
\hline Year dummy variables? & YES & YES & YES & YES & YES & YES & $\mathrm{NO}$ \\
\hline Region dummy variables? & YES & YES & YES & YES & YES & $\mathrm{NO}$ & $\mathrm{NO}$ \\
\hline State dummy variables? & $\mathrm{NO}$ & $\mathrm{NO}$ & $\mathrm{NO}$ & $\mathrm{NO}$ & $\mathrm{NO}$ & YES & $\mathrm{NO}$ \\
\hline Lagged dependent heights? & $\mathrm{NO}$ & $\mathrm{NO}$ & $\mathrm{NO}$ & $\mathrm{NO}$ & $\mathrm{NO}$ & $\mathrm{NO}$ & YES \\
\hline$R^{2}$ & 0.66 & 0.75 & 0.75 & 0.77 & 0.77 & 0.66 & 0.92 \\
\hline Adjusted $R^{2}$ & 0.61 & 0.71 & 0.71 & 0.74 & 0.74 & 0.63 & 0.88 \\
\hline $\mathrm{N}$ & 54 & 54 & 54 & 80 & 80 & 80 & 20 \\
\hline
\end{tabular}

\subsection{The interaction between income and disease}

In Table 6 we tabulate average cohort statures by IMR and GDP in the year of birth to further explore the role of income and disease, and its interactions in explaining population heights. As expected, cohorts living in regions with a high GDP (higher than the median) in the year of birth are taller, while those cohorts living in regions with a high IMR (higher than the median) in the year of birth are shorter. Furthermore, and consistent with our previous results, the role of income appears to be much more important than that of disease: While differences in average height between cohorts living in regions with a high GDP and those living in regions with a low GDP are substantial (3 cm or more), the differences along the disease dimension (high- versus low-IMR regions) are much smaller $(1.5 \mathrm{~cm}$ or less).

In column 1 of Table 7 we estimate regressions of population height on a dummy variable for cohorts in states with an infant mortality rate higher than the median, a dummy variable for cohorts in states with a $\log (\mathrm{GDP})$ higher than the median, and their interaction, hence replicating the results of Table 6 . Column 2 includes both region and year of birth fixed effects. Finally, column 3 includes the fraction of stayers. The results from column 1 show in row 2 that the average height difference between cohort-region pairs of high- and low- 
GDP in low IMR environments is $3.4 \mathrm{~cm}$ (p-value $<0.01$ ). In high IMR environments, the mean difference in heights, captured by the second linear combination of parameters, is $3 \mathrm{~cm}(\mathrm{p}$-value $<0.01)$. The gap between these differences is not statistically significant, since the coefficient on the interaction of the dummy variables in row 3 is not statistically different from zero. As for the average difference in heights between high- and low-mortality environments, this is only statistically significant in high-income environments (first linear combination of parameters): $-1.5 \mathrm{~cm}$. However, only income differences are associated with height differences, once we control for region and year fixed effects, column 2, and accounting for migration, column 3. The difference in average heights between rich and poor regions is $1.5 \mathrm{~cm}$, no matter what the burden of disease is. All in all, these results reinforce the role of income, not disease, in explaining population heights in our context.

\begin{tabular}{cc|ccc}
\hline \hline \multicolumn{4}{c}{ Table 6. Average height by IMR and GDP } \\
& & \multicolumn{3}{|c}{ IMR } \\
& & \multicolumn{3}{c}{} \\
& Low & High & Total \\
\hline Log(GDP) & Low & 162.7 & 161.6 & 161.9 \\
& & {$[9]$} & {$[31]$} & {$[40]$} \\
& High & 166.1 & 164.6 & 165.8 \\
& & {$[31]$} & {$[9]$} & {$[40]$} \\
& & & \\
& Total & 165.3 & 162.3 & 163.8 \\
& & {$[40]$} & {$[40]$} & {$[80]$} \\
\hline \hline
\end{tabular}

Note: High ( $\geq$ median of the variable).

Number of observations in brackets. 


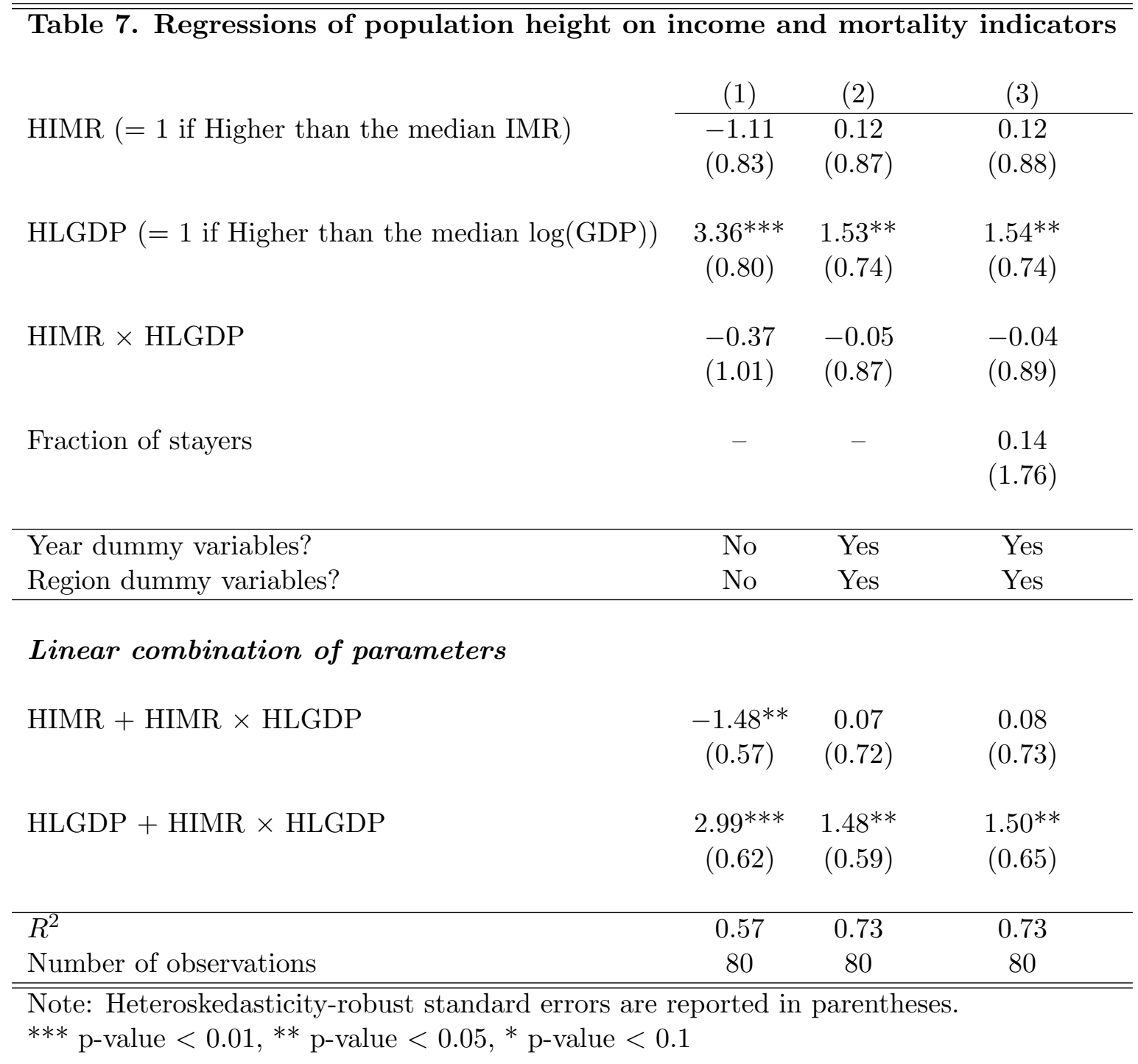

\subsection{Omitted (or mismeasured) determinants of height}

The regressions estimated so far are informative, albeit a bit parsimonious. While conditions in infancy captured by infant mortality and GDP in the year of birth are definitely important for adult height, our previous specification suffers from omitted variable bias if the infant mortality rate (or the GDP in the year of birth) is highly correlated with other contemporaneous environmental and socioeconomic determinants of population heights that vary simultaneously at the state and year level.

Alves and Belluzzo (2004) find that a rise in education, sanitation and per capita income contributed to the decline in IMR in Brazil during the period 1970-2000. If education and 
sanitation indicators in the year of birth are having effects on cohort population heights not only through their effect on the disease environment or income but through other channels, our previous estimates could be biased. For this reason, we gather information on other indicators that may be relevant in shaping the disease environment and may allow individuals to use the existing resources more effectively. Variables that are likely to shape the disease environment include the fraction of the population in urban areas by state and year of birth. The potential differential use of income in generating (and protecting) health is accounted for through the inclusion of the average years of schooling in the state and year of birth. Admittedly, these are crude measures. However our purpose for including them is to assess the extent to which our mortality and income measures are capturing other socioeconomic factors.

In Table 8, column 1, we can see that including both the fraction of the population in urban areas and the average years of schooling does not affect our previous estimates: IMR still does not correlate with population height, while $\log (\mathrm{GDP})$ does. None of these additional factors appears to be statistically significant, either individually or jointly (as judged by the F-test). However, once we replace the region fixed effects with state fixed effects, these additional factors become statistically significant in explaining population heights and their signs flip, although income remains being a strong correlate of adult height.

Is the effect of income on height related to improvements in nutrition? While we do not have information on nutrition at the state and year level, whether improvements in per capita nutrition (or the access to nutrients) are well approximated by increases in real income per head can be further explored by substituting GDP by an alternative incomedriven measure: the headcount ratio, which gives the percentage of population below the poverty line. ${ }^{23}$ In addition, and given that Brazil is the eighth most unequal country in

\footnotetext{
${ }^{23}$ In Brazil the poverty line is set at half the minimum wage in January 1991 (US $\$ 47.12$ PPP, US\$ 1.57 per day).
} 
the world (UNDP 2005) ${ }^{24}$, we also include an indicator of income inequality: the mean log deviation (Theil index). ${ }^{25}$ Unfortunately, these measures are only available for two of the four cohorts under analysis, 1970 and 1980 (Brazil Human Development Atlas, UNPD, 1998). Hence, we are forced to dramatically reduce our sample size, down from 80 to 40 observations. Not surprisingly, the estimates in column 3 indicate that both a higher headcount ratio and a higher Theil index in the year of birth are negatively related to average cohort height, while IMR does not correlate with adult height. ${ }^{26}$ That the income growth during this period was associated to human growth could be explained by improvements in nutrition is consistent with the fact that while food production went up, relative food prices did not increase between 1950 and $1970 .^{27}$

We now turn to explore whether the relationships between height and mortality, and height and income, are non-monotonic. A non-monotonic relationship between mortality and height is plausible if for low levels of IMR there is a negative relationship with height due to the scarring of survivors, while for high-IMR environments there is a positive effect due to selective survival: Weakest individuals at birth (shortest individuals in adulthood) die in the first year of life, so the remaining ones are, on average, taller (see Bozzoli et al. 2009), because their biological height potential is higher. According to the estimates in column 4, we do not find evidence of either non-monotonic effects of IMR or $\log ($ GDP) on height (F-tests are 1.50 and 1.65 , respectively).

\footnotetext{
${ }^{24}$ With a Gini coefficient of 59.3, Brazil is only ahead of Namibia (70.7), Botswana (63.0), Lesotho (63.2), Sierra Leone (62.9), Central African Republic (61.3), Swaziland (60.9), and Guatemala (59.9).

${ }^{25}$ The rationale for the role of income inequality in explaining height is the concavity of the height-toincome relationship at the individual level (Steckel 1995, 2009).

${ }^{26}$ Recent research has explored the role of income inequality in explaining adult heights. In India, Deaton (2008) finds statistically significant effects of income inequality on adult heights, in some specifications, but its sign is the opposite of what one would expect. In Spain, Quintana-Domeque et al. (2011) find a negative relationship between the degree of income inequality in the year of birth, measured by the Gini index, and average height. The effect is statistically significant in several specifications, but its statistical significance disappears once the authors control for IMR.

${ }^{27}$ Reis (2012) suggests that part of the improvements in nutritional outcomes in Brazil in the last decade could be explained by the expansion of social programs such as Bolsa Familia (a conditional cash transfer program).
} 


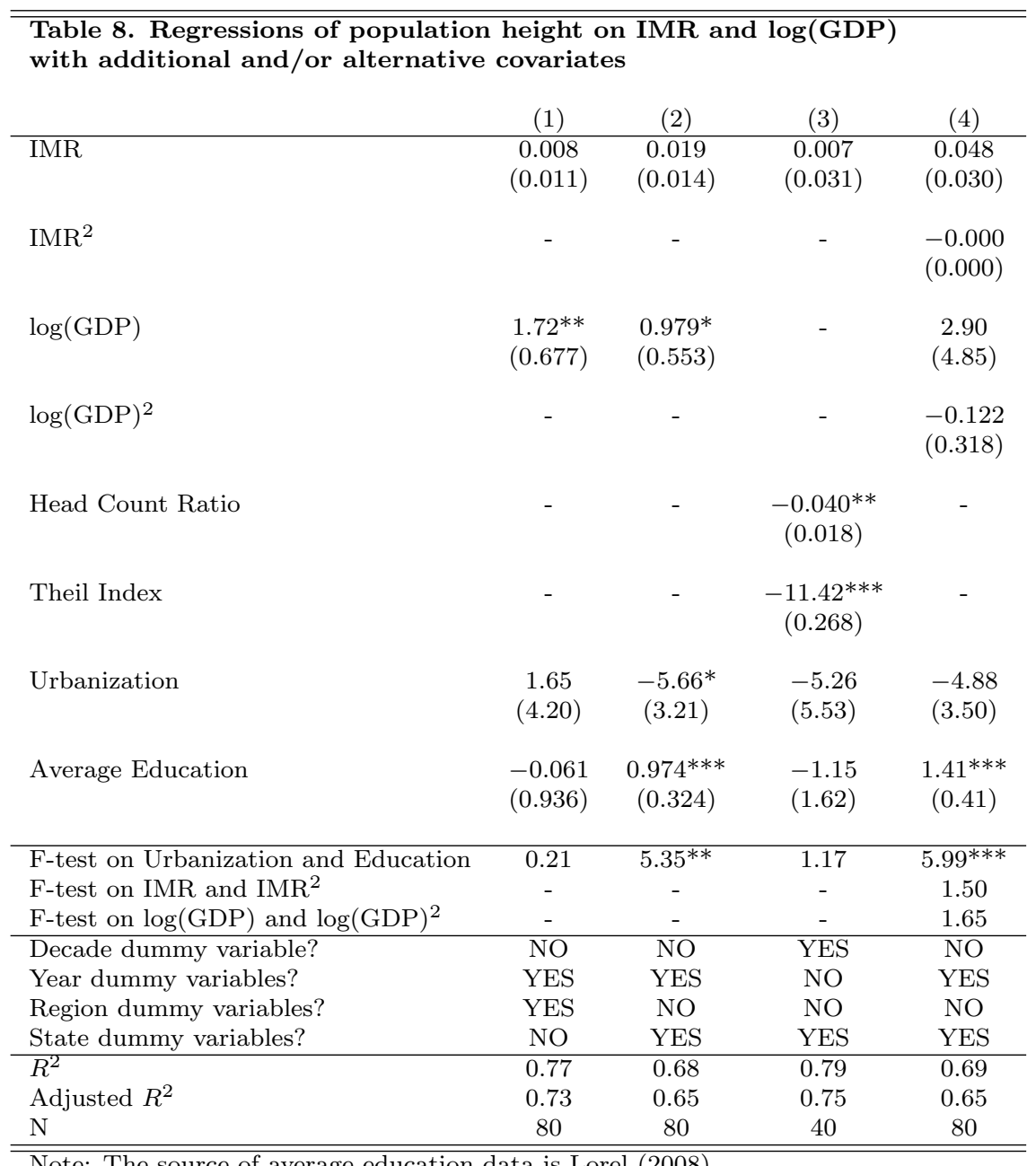

Note: The source of average education data is Lorel (2008).

(1): Heteroskedasticity-robust standard errors are reported in parentheses.

(2)-(4): Clustered standard errors are reported in parentheses.

$* * *$ p-value $<0.01, * *$ p-value $<0.05,{ }^{*}$ p-value $<0.1$

Finally, it is important to note that both IMR and GDP in the year of birth may well be correlated with prenatal or postnatal conditions that also matter for adult height. On the other hand, if income at birth is having a "causal" effect on population heights, economic conditions before birth should not have any effect on heights conditional on income in the year of birth. We implement such a falsification or placebo test in Table 9. In column 1 we regress population height on IMR and $\log (\mathrm{GDP})$ in the year of birth, $\log (\mathrm{GDP})$ five years before birth, and region and year of birth fixed effects. Reassuringly, the estimates from this column show that income before birth does not correlate with height, but income in 


\begin{tabular}{|c|c|c|c|c|c|}
\hline & $(1)$ & $(2)$ & (3) & (4) & $(5)$ \\
\hline IMR & $\begin{array}{c}0.009 \\
(0.010)\end{array}$ & $\begin{array}{c}0.009 \\
(0.010)\end{array}$ & - & $\begin{array}{c}0.104 \\
(0.269)\end{array}$ & $\begin{array}{c}0.002 \\
(0.265)\end{array}$ \\
\hline $\log (\mathrm{GDP})$ & $\begin{array}{l}1.75^{* *} \\
(0.798)\end{array}$ & - & $\begin{array}{c}2.02^{* * *} \\
(0.421)\end{array}$ & $\begin{array}{l}1.80^{* *} \\
(0.820)\end{array}$ & - \\
\hline $\log ($ GDP $) 5$ years before birth & $\begin{array}{l}-0.295 \\
(0.700)\end{array}$ & $\begin{array}{r}-0.050 \\
(0.588)\end{array}$ & - & $\begin{array}{l}-0.246 \\
(0.718)\end{array}$ & $\begin{array}{l}-0.050 \\
(0.593)\end{array}$ \\
\hline $\log (\mathrm{GDP}) 0-5$ years after birth & - & $\begin{array}{c}2.05^{* * *} \\
(0.679)\end{array}$ & - & - & $\begin{array}{c}2.05^{* * *} \\
(0.684)\end{array}$ \\
\hline Pre-adult mortality rate & - & - & $\begin{array}{c}0.007 \\
(0.009)\end{array}$ & $\begin{array}{l}-0.081 \\
(0.228)\end{array}$ & $\begin{array}{c}0.006 \\
(0.225)\end{array}$ \\
\hline Year dummy variables? & YES & YES & YES & YES & YES \\
\hline Region dummy variables? & YES & YES & YES & YES & YES \\
\hline$R^{2}$ & 0.77 & 0.78 & 0.77 & 0.77 & 0.77 \\
\hline Adjusted $R^{2}$ & 0.74 & 0.75 & 0.74 & 0.73 & 0.74 \\
\hline $\mathrm{N}$ & 80 & 80 & 80 & 80 & 80 \\
\hline
\end{tabular}

Note: Heteroskedasticity-robust standard errors are reported in parentheses. $* * *$ p-value $<0.01,{ }^{* *}$ p-value $<0.05,{ }^{*}$ p-value $<0.1$

the year of birth does. Column 2 replaces $\log (\mathrm{GDP})$ in the year of birth with $\log (\mathrm{GDP})$ during early childhood (i.e., 0-5 years after birth). As previously, income before birth is not correlated with adult height, but income during early childhood is an important correlate of it, consistent with the idea that the income environment that is relevant for adult height operates not just in the year of birth. The point estimate is higher than the one corresponding to $\log (\mathrm{GDP})$ in the year of birth in column 1, and its standard error lower, which may reflect that the new variable, the mean of $\log (\mathrm{GDP}) \mathrm{s}$, contains less (classical) measurement error. ${ }^{28}$

Our analysis shows that IMR is not a robust correlate of height. Although this finding

\footnotetext{
${ }^{28}$ The $\log (\mathrm{GDP}) 0-5$ years after birth is computed as the average of $\log (\mathrm{GDP})$ in the year of birth and the $\log (\mathrm{GDP}) 5$ years after birth.
} 
is consistent with the burden of disease being of much less importance than income in developing countries, there are other plausible alternatives. Perhaps IMR is not a good proxy of the disease environment in Brazil, or selection and scarring effects are exactly offsetting each other. Neither the first nor the second alternative appears to be very plausible in our context. Given the wide range of variation in IMR (from 48.99 to 199.04 per 1,000 live births), if selection and scarring effects were exactly offsetting each other, one would expect to find a non-monotonic relationship between population stature and IMR, and we do not find evidence of that in our data. As a further attempt to investigate this issue, one could control for the mortality rate before the cohort reaches adulthood. Indeed, the high pre-adult mortality rates in the developing world are one of their distinctive features. This allows us to investigate the role of an alternative measure of the burden of disease in determining adult height.

Unfortunately, we do not have data on pre-adult mortality rates, either at the state or at the country level in the years of our analysis. Nevertheless, we use the estimated quinquennial ratios of 0-15 mortality to 0-1 mortality in Latin America and the Caribbean for the periods 1950-54, 1960-64, 1970-74 and 1980-84 (Table 4 in Bozzoli et al., 2009) to estimate pre-adult mortality rates as the product of infant mortality rates and the estimated quinquennial ratios. ${ }^{29}$ The corresponding ratios are 1.21 in 1950-54, 1.18 in 1960-64, 1.17 in 1970-74 and 1.15 in 1980-84. Column 3 reports the results of a regression of height on $\log (\mathrm{GDP})$ and the estimated pre-adult mortality rate, controlling for region and year fixed effects. The role of our estimated pre-adult mortality rate is null. ${ }^{30}$ In column 4 , where we add IMR and income before birth, pre-adult mortality rate attracts a negative sign, which is the opposite of what one would expect under selective mortality of the "weakest" (shortest).

\footnotetext{
${ }^{29}$ The quinquennial mortality ratio for the period 1950-54 is multiplied by the infant mortality rate in the year 1950 to obtain an estimate of the pre-adult mortality rate in 1950. Pre-adult mortality rates for the remaining years are similarly estimated.

${ }^{30}$ Note that while the infant mortality rate varies both at the state and year levels, the estimated quinquennial ratios only have time-series variation. Not only that, but the estimated quinquennial ratio refers to the whole Latin American and the Caribbean. In addition, we must bear in mind that, if our estimated pre-adult mortality rate was pure white noise, its estimated coefficient would be zero.
} 
Finally, column 5 is a repetition of column 4 with income in the year of birth being replaced by income during childhood. Neither IMR nor pre-adult mortality rate is correlated with adult height.

\subsection{External validity}

In order to assess the external validity of our estimates, one must take into account the "contour conditions" of the period under analysis, 1950-1980, and how they compare with the pre-1950 and post-1980 conditions. In particular, the early 80s and 90s were marked by stagnant periods with price instability. For example, the increase in relative prices of food after 1980 could have deteriorated nutrition. In this regard, Thomas and Strauss (1995) show that higher prices of both dairy products and sugar negatively affected child health in the mid-70s. Future research could investigate the existence of a "structural break" (post 1980) in the relationship between height, IMR and GDP using (adult) height data for those born in 1980, 1990 and $2000 .^{31}$

\section{Conclusion}

We have used data on four birth cohorts from twenty Brazilian states to analyze the relationship among infant mortality, real income per capita and adult height for the period 1950-1980. Controlling for regional and time fixed effects, infant mortality in the year of birth does not correlate with average adult height, while real income per capita does. Our results are robust to a battery of robustness checks. Using a useful bracketing property of the (state) fixed effects and lagged dependent variables (heights) estimators, we find that an increase in the real GDP per capita of the magnitude seen during the period is associated with $43 \%-68 \%$ of the approximately $3 \mathrm{~cm}$ increase in average height in the same time span. The increase in average height of Brazilian people, $3 \mathrm{~cm}$, is substantial. To put it in context,

\footnotetext{
${ }^{31}$ Note that the relationship between infant mortality rate and height in previous periods may have been different as well.
} 
during the same period, England and the US experienced increases of $1 \mathrm{~cm}$, Ireland of 2 $\mathrm{cm}$, Greece of $3 \mathrm{~cm}$, Portugal of $4 \mathrm{~cm}$, and Spain of $5 \mathrm{~cm}$ (Bozzoli et al., 2009).

While our findings contrast with recent results for developed countries (Bozzoli et al., 2009, Quintana-Domeque et al., 2011), where disease, not income, has been the constraining factor on human growth, at least since 1950, they are consistent with new evidence reported by Coffey (2013) on the determinants of stature in India, a large developing country, and the effects of GDP fluctuations on birth weight in Argentina (Bozzoli and Quintana-Domeque, 2014), given that birth weight and adult height show a strong correlation (Henrik et al., 1999). Thus, the role of income in the year of birth in explaining adult health is not something affecting only cohorts born in the past, but also cohorts born nowadays in developing countries.

\section{References}

Alves, Denisard and Walter Belluzzo. 2004. "Infant mortality and child health in Brazil." Economics \& Human Biology 2 (3):391-410.

Angrist, Joshua D. and Jörn-Steffen Pischke. 2009. Mostly Harmless Econometrics: An Empiricist's Companion. Princeton University Press.

Azzoni, Carlos Roberto. 1997. "Concetração regional e dispersão das rendas per capita estaduais: análise a partir de séries históricas estaduais de PIB, 1939-1995." Estudos Econômicos 27 (3):341-393.

Batty, G. David, Martin J. Shipley, David Gunnell, Rachel Huxley, Mika Kivimaki, Mark Woodward, Crystal Man Ying Lee, and George Davey Smith. 2009. "Height, wealth, and health: An overview with new data from three longitudinal studies." Economics \& Human Biology 7 (2):137-152. 
Bozzoli, Carlos, Angus Deaton, and Climent Quintana-Domeque. 2009. "Adult height and childhood disease." Demography 46 (4):647-669.

Bozzoli, Carlos and Climent Quintana-Domeque. 2014. "The Weight of the Crisis: Evidence from Newborns in Argentina." Review of Economics and Statistics 96 (3).

Case, Anne and Christina Paxson. 2008. "Stature and Status: Height, Ability, and Labor Market Outcomes." Journal of Political Economy 116 (3):499-532.

Coffey, Diane. 2013. "Maternal nutrition, early life mortality and height in India." Princeton University, mimeo .

Curi, Andréa Zaitune and Naércio Aquino Menezes-Filho. 2009. "A relação entre altura, escolaridade, ocupação e salários no Brasil." Pesquisa e Planejamento Econômico $38(3): 414-458$.

David Leon, Martin Shipley David Strachan, George Davey Smith. 1995. "Adult height and mortality in London: early life, socioeconomic status, or shrinkage." Journal of Epidemiology and Community Health 49:5-9.

Deaton, Angus. 2008. "Height, Health, and Inequality: The Distribution of Adult Heights in India." American Economic Review, Papers 65 Proceedings 98 (2):468-74.

Deaton, Angus and Raksha Arora. 2009. "Life at the top: The benefits of height." Economics E Human Biology 7 (2):133-136.

Fogel, Robert William. 2004. The Escape from Hunger and Premature Death, 1700-2100. Cambridge University Press.

Guryan, Jonathan. 2001. "Desegregation and Black Dropout Rates." NBER Working Paper No. 8345 . 
Jousilahti, Pekka, Jaakko Tuomilehto, Erkki Vartiainen, Johan Eriksson, and Pekka Puska. 2000. "Relation of adult height to cause-specific and total mortality: a prospective followup study of 31,199 middle-aged men and women in Finland." American Journal of Epidemiology 151 (11):1112-1120.

Kock, Daniel. 2011. "Waaler revisited: the anthropometrics of mortality." Economics \&6 Human Biology 9 (1):106-117.

Komlos, John. 1998. "Shrinking in a growing economy? The mystery of physical stature during the Industrial Revolution." Journal of Economic History 58 (3):779-802.

Kopczyński, Michal. 2011. "The physical stature of Jewish men in Poland in the second half of the 19th century." Economics \& Human Biology 9 (2):203-210.

Lorel, Benoit. 2008. "Assessing Brazilian Educational Inequalities." Revista Brasileira de Economia $62(1): 31-56$.

Lundborg, Petter, Paul Nystedt, and Dan-Olof Rooth. 2009. "The Height Premium in Earnings: The Role of Physical Capacity and Cognitive and Non-Cognitive Skills." IZA Discussion Papers 4266, Institute for the Study of Labor (IZA).

Monasterio, Leonardo M., Luiz Paulo Noguerol, and Claudio Djissey Shikida. 2010. "Growth and Inequalities of Height in Brazil, 1939-1981." In Living Standards in Latin American History: Height, Welfare, and Development, 1750-2000, edited by Ricardo D. Salvatore, John H. Coatsworth, and Amílcar E. Challú, David Rockefeller Center for Latin American Studies, Series on Latin American Studies. Harvard University Press, 167-196.

Peracchi, Franco and Emilia Arcaleni. 2011. "Early-life environment, height and BMI of young men in Italy." Economics $\mathscr{E}$ Human Biology 9 (3):251 - 264.

Quintana-Domeque, Climent, Carlos Bozzoli, and Mariano Bosch. 2011. "Infant mortality and adult stature in Spain." Social Science 8 Medicine 72 (11):1893-1903. 
Reis, Mauricio. 2012. "Differences in nutritional outcomes between Brazilian white and black children." Economics $\&$ Human Biology 10 (2):174 - 188.

Salvatore, Ricardo D. 2009. "Stature growth in industrializing Argentina: The Buenos Aires industrial belt 1916-1950." Explorations in Economic History 46 (1):70 - 92.

Schultz, T. Paul. 2003. "Wage rentals for reproducible human capital: evidence from Ghana and the Ivory Coast." Economics \& Human Biology 1 (3):331-366.

2005. "Productive Benefits of Health: Evidence from Low-Income Countries." IZA Discussion Papers 1482, Institute for the Study of Labor (IZA).

Silventoinen, Karri. 2003. "Determinants of variation in adult height." Journal of Biosocial Science 35 (2):263-285.

Sørensen, Henrik, Svend Sabroe, Kenneth Rottiman, Matthew Gillman, Flemming Steffonsen, Peer Fischer, and Thorkild Serensen. 1999. "Birth weight and length as predictors for adult height." American Journal of Epidemiology 149 (8):726-729.

Steckel, Richard H. 1995. "Stature and the Standard of Living." Journal of Economic Literature 33 (4):1903-1940.

—. 2009. "Heights and human welfare: Recent developments and new directions." Explorations in Economic History 46 (1):1-23.

Thomas, Duncan and John Strauss. 1995. "Health, wealth and wages of men and women in urban Brazil." RAND Working Paper 11.

UNPD. 1998. Atlas do Desenvolvimento Humano no Brasil. United Nations.

van den Berg, Gerard J., Petter Lundborg, Paul Nystedt, and Dan-Olof Rooth. 2012. "Critical Periods during Childhood and Adolescence: A Study of Adult Height among Immigrant Siblings." Working Papers 2012:23, Lund University, Department of Economics. 
Waaler, Hans Th. 1984. "Height weight and mortality: the Norwegian experience." Acta Medica Scandinavica 215 (S679):1-56. 


\section{Appendix}

Figure 1: Average height by year of birth: Time trend by Brazilian region

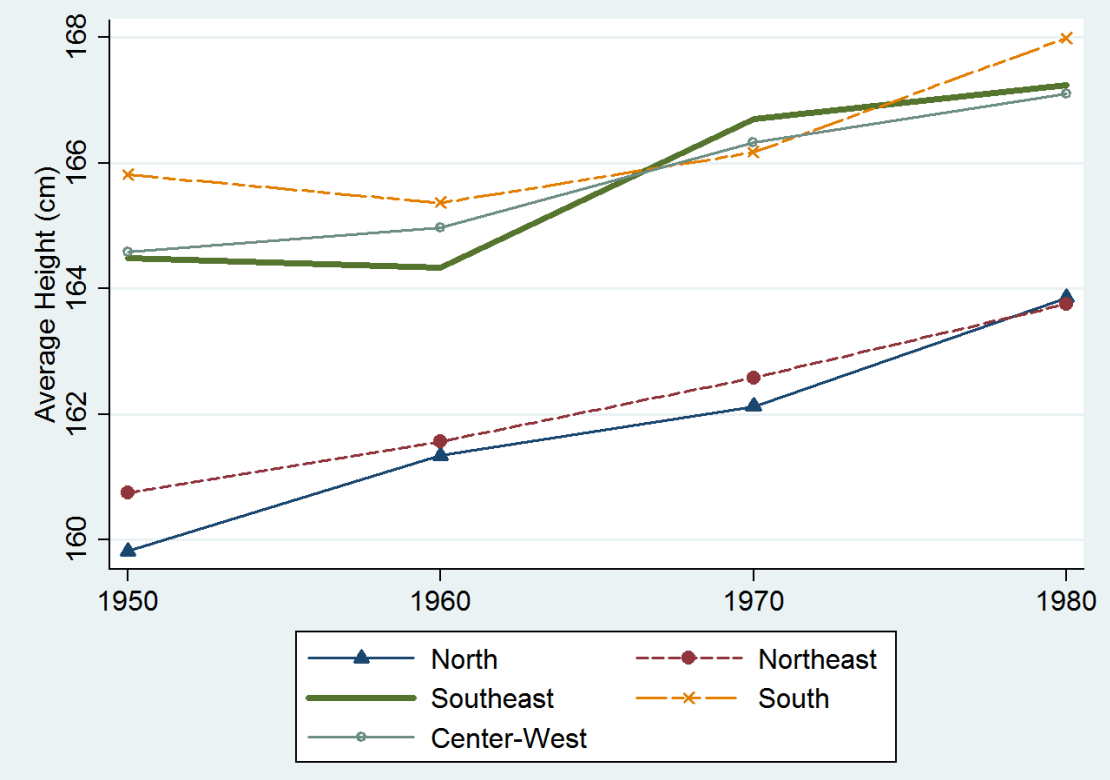

Figure 2: IMR: Time trend by Brazilian region

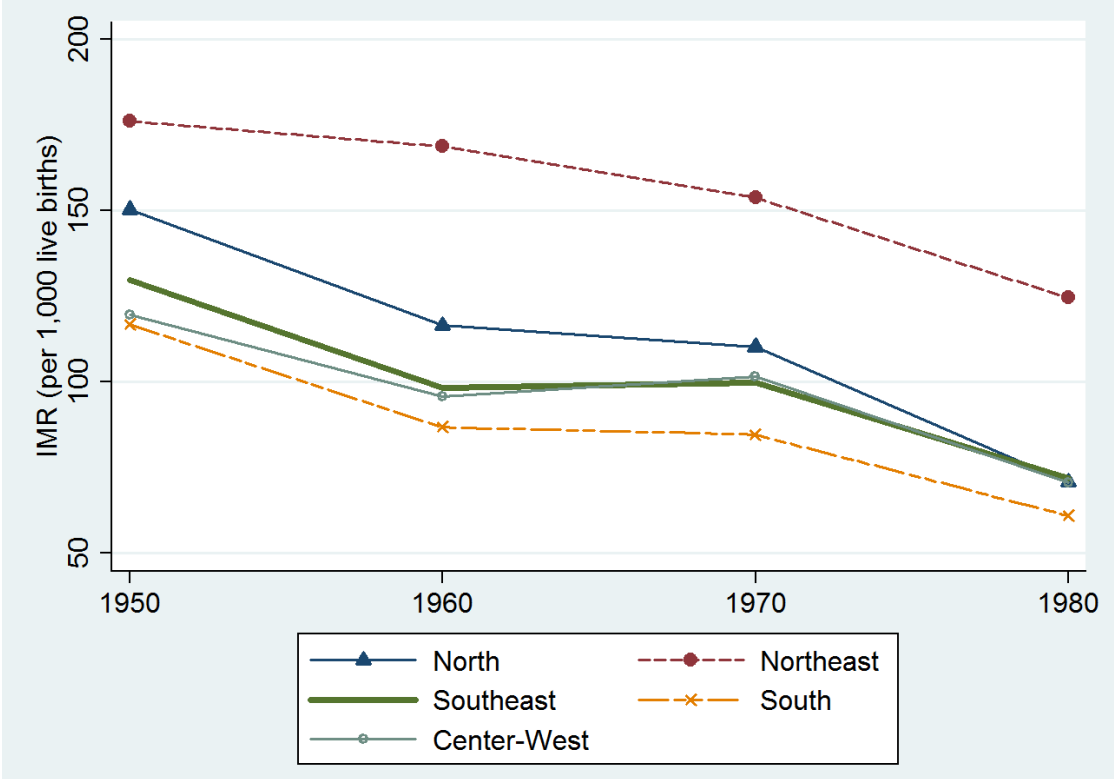


Figure 3: Log(real GDP per capita): Time trend by Brazilian region

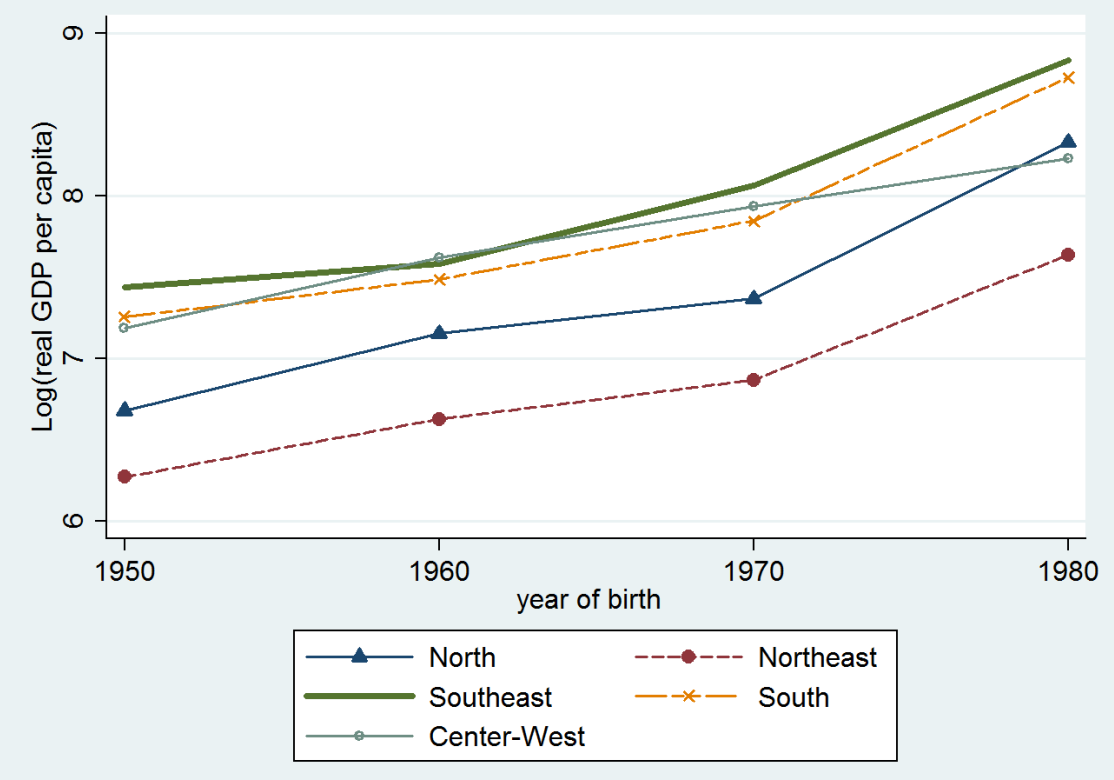




\begin{tabular}{lcccc}
\hline \multicolumn{5}{l}{ Table A1. Average stature by state and year of birth } \\
& & & & \\
& 1950 & 1960 & 1970 & 1980 \\
\hline Alagoas & 160.4 & 161.8 & 162.6 & 163.8 \\
Amazonas & 161.2 & 160.9 & 163.5 & 164.5 \\
Bahia & 163.5 & 161.5 & 165.4 & 166.0 \\
Ceará & 159.3 & 161.3 & 161.1 & 162.3 \\
Espírito Santo & 163.6 & 162.9 & 166.2 & 166.6 \\
Goiás & 164.2 & 165.6 & 166.1 & 167.7 \\
Maranhão & 156.7 & 158.7 & 161.4 & 161.0 \\
Mato Grosso & 165.0 & 164.3 & 166.5 & 166.5 \\
Minas Gerais & 162.7 & 163.8 & 165.3 & 166.8 \\
Pará & 158.4 & 161.8 & 160.8 & 163.2 \\
Paraíba & 160.2 & 161.9 & 162.5 & 164.6 \\
Paraná & 165.5 & 164.6 & 166.2 & 167.2 \\
Pernambuco & 160.8 & 162.4 & 164.0 & 166.0 \\
Piauí & 160.3 & 160.3 & 161.8 & 160.7 \\
Rio Grande do Norte & 161.4 & 160.4 & 161.2 & 163.8 \\
Rio Grande do Sul & 164.9 & 165.2 & 165.1 & 167.5 \\
Rio de Janeiro & 163.9 & 164.7 & 168.7 & 167.2 \\
Santa Catarina & 167.1 & 166.3 & 167.2 & 169.2 \\
São Paulo & 167.7 & 166.0 & 166.6 & 168.4 \\
Sergipe & 164.3 & 165.7 & 163.2 & 165.7 \\
\hline Mean & 162.6 & 163.0 & 164.3 & 165.4 \\
\hline \hline
\end{tabular}

\begin{tabular}{lcccc}
\hline \multicolumn{4}{l}{ Table A2. IMR by state and year of birth } \\
& \multicolumn{4}{l}{} \\
& 1950 & 1960 & 1970 & 1980 \\
\hline Alagoas & 184.9 & 182.3 & 167.9 & 140.5 \\
Amazonas & 153.8 & 119.2 & 110.4 & 67.5 \\
Bahia & 167.3 & 149.9 & 132.8 & 96.0 \\
Ceará & 166.3 & 175.4 & 156.5 & 140.1 \\
Espírito Santo & 126.1 & 96.4 & 96.2 & 60.7 \\
Goiás & 128.6 & 107.6 & 106.6 & 74.4 \\
Maranhão & 150.8 & 133.2 & 131.6 & 106.3 \\
Mato Grosso & 110.4 & 83.9 & 96.5 & 67.0 \\
Minas Gerais & 141.1 & 113.4 & 110.2 & 76.2 \\
Pará & 146.9 & 113.7 & 110.1 & 73.9 \\
Paraíba & 194.5 & 192.9 & 175.3 & 151.3 \\
Paraná & 139.2 & 104.4 & 97.9 & 71.6 \\
Pernambuco & 193.6 & 184.9 & 165.4 & 136.9 \\
Piauí & 146.5 & 136.9 & 130.1 & 96.4 \\
Rio Grande do Norte & 199.0 & 198.2 & 176.6 & 146.9 \\
Rio Grande do Sul & 99.0 & 68.6 & 71.0 & 48.5 \\
Rio de Janeiro & 124.0 & 91.3 & 98.7 & 75.9 \\
Santa Catarina & 111.9 & 87.3 & 84.9 & 62.5 \\
São Paulo & 128.1 & 91.6 & 94.2 & 74.7 \\
Sergipe & 182.7 & 165.0 & 148.0 & 106.4 \\
\hline Mean & 149.7 & 129.8 & 123.0 & 93.7 \\
\hline \hline
\end{tabular}




\begin{tabular}{lcccc}
\hline \hline Table A3. Log(GDP) & by state and year of birth \\
& 1950 & 1960 & 1970 & 1980 \\
\hline Alagoas & 6.3 & 6.7 & 7.0 & 7.8 \\
Amazonas & 6.9 & 7.3 & 7.5 & 8.6 \\
Bahia & 6.3 & 6.8 & 7.2 & 8.1 \\
Ceará & 6.3 & 6.6 & 6.8 & 7.6 \\
Espírito Santo & 7.0 & 7.0 & 7.6 & 8.5 \\
Goiás & 6.7 & 7.0 & 7.4 & 8.2 \\
Maranhão & 5.9 & 6.3 & 6.6 & 7.3 \\
Mato Grosso & 7.6 & 8.2 & 8.5 & 8.2 \\
Minas Gerais & 6.9 & 7.1 & 7.5 & 8.5 \\
Pará & 6.5 & 7.0 & 7.2 & 8.1 \\
Paraíba & 6.4 & 6.8 & 6.7 & 7.4 \\
Paraná & 7.4 & 7.5 & 7.6 & 8.6 \\
Pernambuco & 6.7 & 7.0 & 7.3 & 8.0 \\
Piauí & 5.7 & 6.0 & 6.4 & 7.1 \\
Rio Grande do Norte & 6.5 & 6.9 & 6.8 & 7.8 \\
Rio Grande do Sul & 7.3 & 7.6 & 8.1 & 8.9 \\
Rio de Janeiro & 8.0 & 8.1 & 8.5 & 9.0 \\
Santa Catarina & 7.0 & 7.3 & 7.8 & 8.8 \\
São Paulo & 7.9 & 8.1 & 8.7 & 9.3 \\
Sergipe & 6.3 & 6.7 & 7.1 & 7.8 \\
\hline Mean & 6.8 & 7.1 & 7.4 & 8.2 \\
\hline \hline
\end{tabular}




\begin{tabular}{lcccccc}
\hline \multicolumn{7}{l}{ Table A4. Regressions of male height on male IMR and $\log (\mathbf{G D P})$} \\
& $(1)$ & $(2)$ & $(3)$ & $(4)$ & $(5)$ & $(6)$ \\
\hline$I M R^{\text {male }}$ & $-0.041^{* * *}$ & 0.011 & - & - & -0.003 & 0.006 \\
& $(0.005)$ & $(0.011)$ & & & $(0.007)$ & $(0.009)$ \\
$\log (\mathrm{GDP})$ & & & & & \\
& - & - & $2.63^{* * *}$ & $2.33^{* * *}$ & $2.53^{* * *}$ & $2.30^{* * *}$ \\
& & & $(0.23)$ & $(0.51)$ & $(0.38)$ & $(0.51)$ \\
\hline Year dummy variables? & NO & YES & NO & YES & NO & YES \\
Region dummy variables? & NO & YES & NO & YES & NO & YES \\
\hline$R^{2}$ & 0.35 & 0.66 & 0.57 & 0.74 & 0.57 & 0.74 \\
Adjusted $R^{2}$ & 0.34 & 0.62 & 0.57 & 0.71 & 0.56 & 0.71 \\
$\mathrm{~N}$ & 80 & 80 & 80 & 80 & 80 & 80 \\
\hline \hline
\end{tabular}

Note: Heteroskedasticity-robust standard errors are reported in parentheses.

$I M R^{\text {male }}=\left[\frac{2\left(1+\pi_{s}\right)}{2+\pi_{s}}\right] \times I M R$ where $\pi_{s}=\frac{I M R_{r, 1980}^{\text {male }}}{I M R_{r, 1980}^{\text {female }}}, r$ is region, and $s$ is state.

$\pi_{s}$ is computed from http://seculoxx.ibge.gov.br where $I M R_{r, 1980}=\frac{1}{2} \times\left(I M R_{r, 1980}^{\text {male }}+I M R_{r, 1980}^{\text {male }}\right)$.

$* * *$ p-value $<0.01, * *$ p-value $<0.05,{ }^{*}$ p-value $<0.1$

\begin{tabular}{lcccccc}
\hline \hline \multicolumn{7}{l}{ Table A5. Regressions of female height on female IMR and $\log (\mathbf{G D P})$} \\
& $(1)$ & $(2)$ & $(3)$ & $(4)$ & $(5)$ & $(6)$ \\
\hline IMR female & $-0.044^{* * *}$ & 0.022 & - & - & -0.006 & 0.017 \\
& $(0.005)$ & $(0.014)$ & & & $(0.008)$ & $(0.012)$ \\
$\log (\mathrm{GDP})$ & & & & & \\
& & - & $2.64^{* * *}$ & $1.94^{* * *}$ & $2.43^{* * *}$ & $1.86^{* * *}$ \\
& & & $(0.23)$ & $(0.46)$ & $(0.39)$ & $(0.43)$ \\
\hline Year dummy variables? & $\mathrm{NO}$ & YES & NO & YES & NO & YES \\
Region dummy variables? & NO & YES & NO & YES & NO & YES \\
\hline$R^{2}$ & 0.39 & 0.68 & 0.61 & 0.72 & 0.61 & 0.73 \\
Adjusted $R^{2}$ & 0.39 & 0.64 & 0.60 & 0.69 & 0.60 & 0.70 \\
$\mathrm{~N}$ & 80 & 80 & 80 & 80 & 80 & 80 \\
\hline \hline
\end{tabular}

Note: Heteroskedasticity-robust standard errors are reported in parentheses.

$I M R^{\text {female }}=\left[\frac{2}{2+\pi_{s}}\right] \times I M R$ where $\pi_{s}=\frac{I M R_{r, 1980}^{\text {male }}}{I M R_{r, 1980}^{\text {female }}}, r$ is region, and $s$ is state.

$\pi_{s}$ is computed from http://seculoxx.ibge.gov.br where $I M R_{r, 1980}=\frac{1}{2} \times\left(I M R_{r, 1980}^{\text {male }}+I M R_{r, 1980}^{\text {male }}\right)$.

*** p-value $<0.01, * *$ p-value $<0.05, *$ p-value $<0.1$ 


\begin{tabular}{|c|c|c|c|c|}
\hline & State Fixed Effects & Lagged & Dependen & Heights \\
\hline & (1) & $(2)$ & (3) & (4) \\
\hline$I M R^{\text {male }}$ & $\begin{array}{c}0.033 \\
(0.019)\end{array}$ & $\begin{array}{l}-0.004 \\
(0.005)\end{array}$ & $\begin{array}{l}-0.004 \\
(0.007)\end{array}$ & $\begin{array}{c}0.005 \\
(0.008)\end{array}$ \\
\hline $\log (\mathrm{GDP})$ & $\begin{array}{l}1.69^{* *} \\
(0.640)\end{array}$ & $\begin{array}{c}1.72^{* * *} \\
(0.397)\end{array}$ & $\begin{array}{l}1.38^{* *} \\
(0.551)\end{array}$ & $\begin{array}{l}1.82^{* *} \\
(0.765)\end{array}$ \\
\hline Height in 1950 & - & $\begin{array}{c}0.345^{* * *} \\
(0.110)\end{array}$ & $\begin{array}{c}0.291^{* *} \\
(0.116)\end{array}$ & $\begin{array}{c}0.487^{* * *} \\
(0.162)\end{array}$ \\
\hline Height in 1960 & - & - & $\begin{array}{c}0.290 \\
(0.169)\end{array}$ & $\begin{array}{c}0.304 \\
(0.186)\end{array}$ \\
\hline Height in 1970 & - & - & - & $\begin{array}{l}-0.027 \\
(0.135)\end{array}$ \\
\hline Year dummy variables? & YES & YES & YES & $\mathrm{NO}$ \\
\hline State dummy variables? & YES & $\mathrm{NO}$ & $\mathrm{NO}$ & $\mathrm{NO}$ \\
\hline$R^{2}$ & 0.49 & 0.70 & 0.77 & 0.91 \\
\hline Adjusted $R^{2}$ & 0.45 & 0.67 & 0.74 & 0.87 \\
\hline $\mathrm{N}$ & 80 & 60 & 40 & 20 \\
\hline
\end{tabular}

\begin{tabular}{|c|c|c|c|c|}
\hline & State Fixed Effects & Lagged & ependent & Heights \\
\hline & $(1)$ & $(2)$ & $(3)$ & $(4)$ \\
\hline$I M R^{\text {female }}$ & $\begin{array}{l}-0.003 \\
(0.015)\end{array}$ & $\begin{array}{c}0.007 \\
(0.007)\end{array}$ & $\begin{array}{c}0.010 \\
(0.009)\end{array}$ & $\begin{array}{c}0.018 \\
(0.013)\end{array}$ \\
\hline $\log (\mathrm{GDP})$ & $\begin{array}{l}-0.032 \\
(0.531)\end{array}$ & $\begin{array}{l}1.21^{* *} \\
(0.478)\end{array}$ & $\begin{array}{c}1.25^{*} \\
(0.668)\end{array}$ & $\begin{array}{l}0.845 \\
(1.04)\end{array}$ \\
\hline Height in 1950 & - & $\begin{array}{c}0.640^{* * *} \\
(0.114)\end{array}$ & $\begin{array}{c}0.280 \\
(0.230)\end{array}$ & $\begin{array}{c}0.024 \\
(0.400)\end{array}$ \\
\hline Height in 1960 & - & - & $\begin{array}{c}0.389^{* *} \\
(0.141)\end{array}$ & $\begin{array}{c}0.630^{* *} \\
(0.283)\end{array}$ \\
\hline Height in 1970 & - & - & - & $\begin{array}{c}0.302 \\
(0.199)\end{array}$ \\
\hline Year dummy variables? & YES & YES & YES & $\mathrm{NO}$ \\
\hline State dummy variables? & YES & $\mathrm{NO}$ & $\mathrm{NO}$ & $\mathrm{NO}$ \\
\hline$R^{2}$ & 0.71 & 0.77 & 0.76 & 0.84 \\
\hline Adjusted $R^{2}$ & 0.69 & 0.75 & 0.72 & 0.79 \\
\hline $\mathrm{N}$ & 80 & 60 & 40 & 20 \\
\hline
\end{tabular}

